\title{
Falls among physically active elderly in senior housings, Bangkok, Thailand: situations and perceptions
}

This article was published in the following Dove Press journal:

Clinical Interventions in Aging

\author{
Natthawadee Maneeprom \\ Surasak Taneepanichskul \\ Alessio Panza \\ College of Public Health Sciences, \\ Chulalongkorn University, Bangkok \\ 10330, Thailand
}

Correspondence: Surasak

Taneepanichskul

College of Public Health Sciences,

Chulalongkorn University, Institute

Building 2-3, Soi Chulalongkorn

62, Phyathai Road, Pathumwan,

Bangkok 10330, Thailand

Tel +6622188193

Fax +66 22556046

Email surasakta@yahoo.com
Purpose: A mixed-method study aimed to assess situations in which falls occur including prevalence and associated risk factors of falls among physically active elderly who are at risk of experiencing a fall in senior housings, Bangkok, Thailand, and their perceptions regarding falls.

Patients and methods: In the first phase, a cross-sectional study was conducted on 64 physically active elderly senior housing residents. Data on sociodemographics, health status, Barthel Index (BI) of activities of daily living, and fall experiences were collected through face-toface interviews. Data on balance scores were obtained from Time Up and Go (TUG) test and Berg Balance Scale (BBS). In the second phase, a qualitative study was conducted on 41 physically active elderly who had experienced falls. Data regarding perception on falls, fall preventions, and fall management, were gathered through in-depth interviews from November 2017 to December 2017.

Results: The prevalence of falls among participants in senior housings was $64.1 \%$. Univariate analysis found that a higher BI was associated with fall $(P<0.004)$. Multivariate analysis using binary logistic regression showed that a higher $\mathrm{BI}(\mathrm{OR}=6.00,95 \% \mathrm{CI}=1.24-29.10)$ together with $\geq 2$ environmental hazards $(\mathrm{OR}=6.33,95 \% \mathrm{CI}=1.24-32.29)$ were associated with fall. The result from content analysis indicated that the elderly were aware that they were at risk of fall. In addition, the elderly also perceived that fall could be avoided even though they did not know how to prevent it. Conclusion: The prevalence of fall among physically active elderly in senior housings was relatively high. A higher BI scale and having $\geq 2$ environmental hazards were associated risk factors of falls. Although the elderly perceived that fall could be avoided, they did not know how to prevent it. The intervention that focuses on environmental modification, balancing enchantment, and education on fall prevention is highly required.

Keywords: fall, elderly, senior housing, perception, Thailand, fall prevention

\section{Introduction}

An aging population is increasing globally. In 2017, the United Nations reported that the global population aged $\geq 60$ years were 962 million worldwide. The number of elderly is expected to double and projected to reach nearly 2.1 billion by 2050 . It means that one in five people will be aged 60 years or older in $2050 .{ }^{1}$ In Thailand $16.5 \%$ of the population was categorized as elderly in 2016, and this situation places Thailand as having the second highest population of elderly in the Southeast Asia region. ${ }^{2}$

Among the aging population, falls are a major public health concern. One-third of the elderly aged $>65$ years experience falls each year. More than 600,000 fatal falls occur annually, making it the second leading cause of unintentional injury related deaths after road traffic injuries. ${ }^{3}$ Furthermore, the elderly who had experienced falls tend to have two to three fall recurrences. ${ }^{4}$ Prevalence of falls was found to be higher in elderly living in 
long-term care institutions than those living in a community. ${ }^{5-7}$ A previous study found that the prevalence of falls among elderly nursing home residents ranged between 50\%-66\%, while a 50\% occurrence was observed among hospitalized patients $^{8}$ and $16.9 \%$ among elderly community dwellers. ${ }^{9}$

Falls are prominent among the external causes of unintentional injury. It is coded as E880-E888 in ICD-9 and as W00W19 in ICD-10, which include a wide range of falls including those on the same level, upper level and other unspecified falls. Falls are commonly defined as "inadvertently coming to rest on the ground, floor or other lower level, excluding intentional change in position to rest in furniture, wall or other objects". 8

Falls lead to hospital admission and long-term health effects. Health care impacts and costs of falls in older adults are significantly increasing globally. ${ }^{10,11}$ In all cost items, hospital admission services take the greatest part by accounting for about $50 \%$ of total fall-related cost. ${ }^{10,12,13}$ In 2015 , the estimated medical cost attributable to fatal and non-fatal falls was $\sim \$ 50.0$ billion. $^{14}$

Falls occur more frequently among; elderly females; $8,15,16$ those who are much older have older age, $8,15,17$ those with insufficient income, those who suffer from cognitive impairment, those who have previous fall experience, those who have poor ability to perform activities of daily living (ADL), those who have gait and balance problems, and those with visual impairments; elderly who use multiple medication or sedatives; ${ }^{15}$ that live alone; ${ }^{18}$ use walking assistive devices $;{ }^{19}$ and exposed to environmental hazards.

A systematic review ${ }^{20}$ and many guidelines ${ }^{4,21}$ indicated that exercise is an effective intervention for fall prevention in the elderly. However, delivering fall prevention exercise is not a "one size fits all" solution. ${ }^{22}$ Tai chi, dancing, and gardening seemed appropriate with mild deficit of strength and balance for those who have no experience of a falls, while Otago exercise $\mathrm{e}^{23}$ and postural stability programs are more appropriate for elderly at a high risk of fall. ${ }^{22}$ In Thailand, the Elderly Handbook: Good Walking, No Falling ${ }^{24}$ indicated exercises specific to physical conditions: 1) bed ridden or elderly who are unable to walk and 2) physically active elderly. To address appropriate intervention, the elderly are needed to be classified according to their physical levels.

Given a rapid growth of the aging population, Thailand is also considered as a potential location of retirement communities for a well-heeled clientele in Asia Pacific. ${ }^{25}$ Therefore, senior housing has also been rapidly developed in this decade in both government and private sectors.

However, lack of studies conducted on to evaluate falls and perceptions among physically active elderly who at risk of fall at senior housing, Bangkok, Thailand. Hence, we chose elderly who were physically active but were at risk of fall as our target group in order to have an insight on how to tackle a fall and to understand fall situations and perceptions of the elderly. The study aimed at assessing the prevalence of falls and associated risk factors among active fall risk elderly living in senior housing, Bangkok, Thailand, and their perceptions regarding falls.

\section{Patients and methods}

\section{Sample size, study design, and procedure}

A mixed-method study consisted of cross-sectional study and qualitative study among physically active elderly at risk of falls residing in two senior housings in Bangkok, Thailand, were purposively selected in this study. In the first phase, data on sociodemographics, health status, physical activities, and fall experiences were collected through face-to-face interviews. Data on balance scores were obtained by asking the eligible participants to perform a task-oriented balance test, which consisted of Timed Up and Go (TUG) test and Berg Balance Scale (BBS). Data collection was used from November 2017 to December 2017.

All 350 elderly who were living in the two senior housings were asked to participate. In order to screen for risks of falling, ${ }^{26}$ the elderly were asked the following key questions: 1) falls experienced in the past year; 2) feeling unsteady when standing or walking; and 3) worries about falling; if elderly said "yes" to any question, the TUG test was conducted to evaluate gait, strength, and balance.

To be an eligible participant, the elderly had to pass the following inclusion criteria: 1 ) age $\geq 60$ years; 2 ) can read and write in Thai language; 3 ) had a Barthel Index (BI) scale $\geq 12$; 4) had fall experience(s) in the past 12 months and/or had TUG test $\geq 20$ seconds; and 5) lived in senior housing for at least 1 month. Overall 91 elderly patients were eligible to be included in our study. From the 91 participants, the elderly diagnosed with dementia $(n=14)$ and hearing impairment $(n=3)$ and those unwilling to participate in this study $(n=10)$ were excluded. Finally, 64 physically active elderly at risk of falls were recruited in to this study. Data collection was performed by a research investigator and two trained research assistants. The fall risk screening and balance tests were performed by research assistants and supervised by the main investigator to ensure the participants' safety.

In the second phase, a qualitative study was also applied through in-depth interviews conducted by the principal investigator among 41 eligible participants who had fall experience(s) in the past 12 months in order to understand their perception on fall prevention. The in-depth interviews 
comprised of following questions: 1) what is your perception of a fall; 2) what do you understand about fall prevention, and 3 ) how to manage a fall, each lasting 35-65 minutes for each participant. The interviews were recorded using a voice recorder application on an iPad, and field notes were performed necessarily. Environmental hazards in the room and resident areas were also observed using a checklist.

Both oral and written informed consent were obtained from all participants. The ethical clearance was approved by the ethics review committee of Research Involving Human Research Subjects, Health Sciences Group, Chulalongkorn University (COA No 201/2560).

\section{Measurements for cross-sectional study} Sociodemographic variables

Sociodemographic variables consisted of four components: 1) demographic variables including sex, age, marital status, education, income, and source of income; ${ }^{18} 2$ ) health variables such as comorbidity, medication, eye sight problem, eye glasses/contact lens utilization, and physical activities; ${ }^{18,21,24}$ 3 ) environment variables such as walking assistive devices and environmental hazards: ${ }^{18,21,24,27}$ and 4) experience of falls including number of fall, place of fall, cause of fall, treatment after a fall, effects of a fall, and duration of hospital admission. Approximately 10-15 minutes was taken by each participant to complete the questionnaire.

\section{ADL}

The physical activity scores were measured by the BI of ADL Thai version. ${ }^{28}$ It is composed of 10 domains such as feeding, grooming, transfer, toilet use, mobility, dressing, stairs, bathing, bowels, and bladder. The correlation with Dynamic Gait Index was excellent with $r=0.67$ among elderly population. ${ }^{29}$ The BI of ADL was translated into Thai version and has been widely used by Ministry of Public Health of Thailand with a high inter-rater reliability between therapists, ${ }^{30}$ and the interclass correlation coefficient (ICC) was $0.87 .{ }^{31}$ The total BI score was 20 and was classified into three groups: 1) dependent or bed ridden (score of 0-4); 2) partially dependent (score of 5-11); and 3) independent or active elderly (score of $\geq 12$ ).

\section{Balance}

The balance measurements were assessed by using TUG and BBS tests. ${ }^{32}$ TUG is a fall risk screening tool, recommended by the Centers of Disease Control and Prevention $(\mathrm{CDC})^{26}$ of USA and Ministry of Public Health of Thailand. ${ }^{24}$ TUG is a task-oriented test. It started with an elderly seated on a straight-backed chair. When the instructor said "go", the elderly raised from the chair, walked $3 \mathrm{~m}$, turned around, came back to the chair, and sat down. The TUG has a good validity $^{33}$ and reliability and is an easy-to-administer clinical tool for assessing balance. ${ }^{34}$ TUG proved to be an accurate measure for screening the risk of falls among elderly with a sensitivity of $73.7 \%$ and a specificity of $65.8 \% .{ }^{35}$ In Thailand, the cutoff point was $\geq 20$ seconds for fall risk. ${ }^{24}$ The BBS Thai version comprised of 14 -items, which were designed to assess balance in various types of patients such as patients with neuromuscular diseases and lower-limb amputations ${ }^{36}$ with fall risk predictive validity (sensitivity was 0.72 , specificity was 0.73 , and accuracy was 0.84$).{ }^{37}$

The BBS is also one of the recommended tools for balance and fall risk assessment by the Ministry of Public Health of Thailand. Item-level scores ranged from 0 to 4, determined by ability to perform the assessed activity. The total score ranged from $0-56$. The elderly were evaluated by performing static and dynamic activities such as sitting unsupported, change of position, sitting to standing, standing to sitting, transfer, standing unsupported, standing with eye closed, standing with feet together, tandem standing, standing on one leg, turning trunk (feet fixed), retrieving objects from floor, turning $360^{\circ}$, stool stepping, and reaching forward while standing.

\section{Knowledge on fall prevention}

A questionnaire of 31 items was used to assess knowledge on fall prevention. Data on intrinsic and extrinsic risk factors of falls were gathered by interviewers. It was a yes-no questionnaire. Item-level ranged from 0 to 1 . The total score ranged from 0 to 31 . The knowledge level was classified into two categories based on mean score. The knowledge level was considered as good if the score was $\geq$ mean and less if the score was $<$ mean. Content validity was derived from literature reviews, ${ }^{24}$ and Cronbach's alpha coefficient was 0.77 .

\section{Statistical analyses}

Quantitative findings were analyzed using SPSS for Windows, version 20 (IBM Corporation, Armonk, NY, USA). Categorical data were presented in frequency and percentage. Numerical data were presented in frequency, percentage, mean, and SD. A chi-squared test was performed in univariate analysis to assess significant factors of fall among active fall risk elderly living in senior housings. Binary logistic regression was performed in multivariate analysis to identify the final significant factors of fall among participants. All variables were analyzed in the multivariate model to examine the effect modifier among variables. A $P$-value of $\leq 0.05$ was considered as a significant level. 
Qualitative findings were analyzed by content analysis. The analysis involved reading field notes, transcripts, and listening to the interviews to gain the general sense of the data. After several readings to ensure immersion in the data, keywords were underlined. Data were coded independently by two research assistants. After careful analysis by the research team, themes and categories were developed. Any disagreements were resolved through discussion.

\section{Results}

\section{Sociodemographic and health characteristics}

Overall 64 elderly at risk of fall were finally recruited into our study, of which $81.2 \%$ were female and $18.8 \%$ were male; mean age \pm SD was $76.4 \pm 9.6$ years. Most of the participants (43.8\%) were married, and $59.4 \%$ had secondary and above educational background. Majority of participants $(85.9 \%)$ reported had sufficient income, and more than half (59.4\%) of the participants received an income from some sources such as pension, interest, business, and/or donation. Moreover, a large number (89.1\%) of participants had eyesight problems and more than a half of participants $(60.9 \%)$ were using eyeglasses. A majority (62.5\%) of participants had hypertension with $81.3 \%$ at risk of fall due to medication, which includes using $\geq 4$ medications, seductives, hypnotics, seizers, and antihypertensives. Walking was found to be the most common form (53.1\%) of physical activity, among participants. However, only $37.5 \%$ of the participants used walking assistive devices, which mostly was cane (25\%; Table 1$)$.

\section{Fall and related factors}

Prevalence of falls was reported among $64.1 \%$ physically active elderly at risk of fall. Majority (43.8\%) of participants had at least one fall experience. Most of the falls happened outside of the senior housing. The major causes of falls were stumbling (39.0\%) and loss of balance (39.0\%). The majority (70.7\%) of the elderly had a fall when walking. The main effects from fall were pain (31.7\%), and more than a half (51.2\%) of participants did not receive any medication (Table 2).

In the univariate analysis as shown in Table 3, some variables such as sex, age, income, eyesight problem, using eyeglasses, TUG score, BBS, comorbidities, medication risk, and environmental hazard were not associated with fall experiences among physically active elderly at risk of fall living in senior housings. Only one significant risk factor associated with fall had a higher BI scale $(P \leq 0.05)$.

Finally, in a multivariate model analysis, a higher BI scale $(\mathrm{OR}=6.00,95 \% \mathrm{CI}=1.24-29.10)$ and $\geq 2$ environmental
Table I Demographics, health characteristics, and environmental hazards $(\mathrm{N}=64)$

\begin{tabular}{|c|c|c|}
\hline Variables & $\mathbf{n}$ & $\%$ \\
\hline \multicolumn{3}{|l|}{ Demographics } \\
\hline \multicolumn{3}{|l|}{ Sex } \\
\hline Female & 52 & 81.2 \\
\hline Male & 12 & 18.8 \\
\hline \multicolumn{3}{|l|}{ Age (years) } \\
\hline 76 up & 33 & 51.6 \\
\hline $60-75$ & 31 & 48.4 \\
\hline \multicolumn{3}{|l|}{ Mean $\pm S D=76.42 \pm 9.58$} \\
\hline \multicolumn{3}{|l|}{ Marital status } \\
\hline Married & 28 & 43.8 \\
\hline Single & 23 & 35.9 \\
\hline Divorce/separate/widow & 13 & 20.3 \\
\hline \multicolumn{3}{|l|}{ Education } \\
\hline Secondary school and above & 38 & 59.4 \\
\hline Primary school & 26 & 40.6 \\
\hline \multicolumn{3}{|l|}{ Income } \\
\hline Enough & 55 & 85.9 \\
\hline Not enough & 9 & 14.1 \\
\hline \multicolumn{3}{|l|}{ Source of income } \\
\hline Not family: pension, interest, business, donation & 38 & 59.4 \\
\hline Family & 26 & 40.6 \\
\hline \multicolumn{3}{|l|}{ Comorbidities } \\
\hline Hypertension & 40 & 62.5 \\
\hline Diabetes mellitus & 15 & 23.4 \\
\hline Osteoarthritis & 15 & 23.4 \\
\hline Dyslipidemia & 13 & 20.3 \\
\hline Pain & 13 & 20.3 \\
\hline Heart disease & 8 & 12.5 \\
\hline Incontinence & 8 & 12.5 \\
\hline Stroke & 4 & 6.3 \\
\hline Postural hypotension & 2 & 3.1 \\
\hline Syncope & 2 & 3.1 \\
\hline Parkinson & 1 & 1.6 \\
\hline Foot ulcer & 0 & 0.00 \\
\hline $\begin{array}{l}\text { Medication risks: using } \geq 4 \text { medications, seductive, } \\
\text { hypnotics, seizers, antihypertensives }\end{array}$ & 52 & 81.3 \\
\hline \multicolumn{3}{|l|}{ Physical functions } \\
\hline \multicolumn{3}{|l|}{ Bl scale, mean $\pm S D=18.36 \pm 2.18$} \\
\hline \multicolumn{3}{|l|}{ TUG test, mean $\pm S D=20.89 \pm 6.84$} \\
\hline \multicolumn{3}{|l|}{ BBS, mean $\pm S D=43.98 \pm I I .05$} \\
\hline $\begin{array}{l}\text { Eyesight problem: short-sightedness, } \\
\text { long-sightedness, cataract, others }\end{array}$ & 57 & 89.1 \\
\hline Using eyeglasses & 39 & 60.9 \\
\hline \multicolumn{3}{|l|}{ Using walking assistive device } \\
\hline No & 40 & 62.5 \\
\hline Yes & 24 & 37.5 \\
\hline
\end{tabular}


Table I (Continued)

\begin{tabular}{|c|c|c|}
\hline Variables & $\mathbf{n}$ & $\%$ \\
\hline \multicolumn{3}{|l|}{ Type of walking assistive device (answered more than I) } \\
\hline Cane & 16 & 25.0 \\
\hline Umbrella & 7 & 10.9 \\
\hline Walker & $\mathrm{I}$ & 1.6 \\
\hline Wheelchair & 4 & 6.3 \\
\hline \multicolumn{3}{|l|}{ Physical activity $>30$ minutes } \\
\hline Every day & 39 & 60.9 \\
\hline No & 14 & 21.9 \\
\hline 3-4 times a week & 6 & 9.4 \\
\hline I-2 times a week & 5 & 7.8 \\
\hline \multicolumn{3}{|l|}{ Type of physical activity (answer more than I) } \\
\hline Walking/jogging & 34 & 53.1 \\
\hline Others: moving arm & 15 & 23.4 \\
\hline Swimming & 3 & 4.7 \\
\hline Tai chi/yoga & I & 1.6 \\
\hline Aerobic dance & 0 & 0.0 \\
\hline \multicolumn{3}{|l|}{ Environmental hazards } \\
\hline \multicolumn{3}{|l|}{ Floor } \\
\hline Uneven ground surface & 23 & 35.9 \\
\hline Disorganized furniture/messy room & 13 & 20.3 \\
\hline Slippery floor & 9 & 14.1 \\
\hline \multicolumn{3}{|l|}{ Stairs and steps } \\
\hline Having stairs and steps & 53 & 82.8 \\
\hline $\operatorname{Dim}$ & 2 & 3.1 \\
\hline Object on stairs/broken stairs/torn carpet on stairs & 0 & 0.0 \\
\hline \multicolumn{3}{|l|}{ Kitchen } \\
\hline Disorganized & 4 & 6.3 \\
\hline \multicolumn{3}{|l|}{ Toilet } \\
\hline No light from bed to toilet & 3 & 4.7 \\
\hline Dim toilet & 2 & 3.1 \\
\hline \multicolumn{3}{|l|}{ Fall prevention knowledge, mean $\pm S D=25.84 \pm 4.80$} \\
\hline Good & 39 & 60.9 \\
\hline Less & 25 & 39.1 \\
\hline
\end{tabular}

Abbreviations: BI, Barthel Index; TUG, Time Up and Go; BBS, Berg Balance Scale.

hazards $(\mathrm{OR}=6.33,95 \% \mathrm{CI}=1.24-32.29)$ were found to be significant risk factors for fall among active elderly living in senior housings in this study (Table 4).

\section{Environmental hazards}

Based on observations, 11 elderly lived in single rooms, 13 elderly lived in shared rooms, eight elderly lived in bungalows, and 32 elderly lived in condominiums. Age-friendly housings were designed: wide door for wheel chair, slope with handle, stairs with handle elevators, and the bathroom with anti-slip floor. The facilities provided were yard and garden. Every room had phone connection to housing staff
Table 2 Prevalence and characteristics of fall

\begin{tabular}{|c|c|c|}
\hline Fall record & $\mathbf{n}$ & $\%$ \\
\hline \multicolumn{3}{|l|}{$\begin{array}{l}\text { Number of falls in past } 12 \text { months prior to this } \\
\text { study }(\mathrm{N}=64)\end{array}$} \\
\hline I time & 28 & 43.8 \\
\hline Non-fallers & 23 & 35.9 \\
\hline$\geq 2$ times & 13 & 20.3 \\
\hline \multicolumn{3}{|l|}{ Place of fall $(n=4 I)$} \\
\hline Outdoor of the senior housing & 20 & 48.8 \\
\hline Inside the room & 16 & 39.0 \\
\hline Community & 5 & 12.2 \\
\hline \multicolumn{3}{|l|}{ Time $(n=4 I)$} \\
\hline Morning & 13 & 31.7 \\
\hline Evening & 12 & 29.3 \\
\hline Afternoon & 10 & 24.4 \\
\hline Night & 6 & 14.6 \\
\hline \multicolumn{3}{|l|}{ Cause of fall $(n=4 I)$, multiple answer } \\
\hline Stumbling & 16 & 39.0 \\
\hline Lost balance & 16 & 39.0 \\
\hline Muscle weakness & 9 & 22.0 \\
\hline Slippery floor & 8 & 19.5 \\
\hline Uneven ground surface & 7 & 17.1 \\
\hline Do not see the object & 6 & 14.6 \\
\hline Vertigo & 2 & 4.9 \\
\hline Inappropriate dress & 1 & 2.4 \\
\hline Dim & 1 & 2.4 \\
\hline Wet floor & 1 & 2.4 \\
\hline $\begin{array}{l}\text { Syncope/sleepy/drunk/inappropriate } \\
\text { shoe/slope }\end{array}$ & 0 & 0.0 \\
\hline \multicolumn{3}{|l|}{ Action while falling $(n=4 I)$} \\
\hline Walking straight & 29 & 70.7 \\
\hline Turning/change position & 6 & 14.6 \\
\hline Housework, gardening & 5 & 12.2 \\
\hline Running & 1 & 2.4 \\
\hline \multicolumn{3}{|l|}{ Effect of fall $(n=4 I)$} \\
\hline Painful & 13 & 31.7 \\
\hline Bruise & 11 & 26.8 \\
\hline No effect & 10 & 24.4 \\
\hline Cannot walk & 6 & 14.6 \\
\hline Wound or scratch & 5 & 12.2 \\
\hline Sprain & 2 & 4.9 \\
\hline Fracture & 1 & 2.4 \\
\hline \multicolumn{3}{|l|}{ Treatment after fall $(n=4 I)$} \\
\hline No medication & 21 & 51.2 \\
\hline $\begin{array}{l}\text { Professional sectors: clinic, pharmacist, } \\
\text { hospital }\end{array}$ & 11 & 26.8 \\
\hline Popular sectors example self-care, caregiver & 8 & 19.5 \\
\hline Folk sector example herb, massage & 1 & 2.4 \\
\hline Hospital administration & 3 & 7.3 \\
\hline
\end{tabular}


Table 3 Univariate analysis of fall characteristics among active fall risk elderly living in senior housings $(\mathrm{N}=64)$

\begin{tabular}{|c|c|c|c|c|c|c|}
\hline \multirow[t]{2}{*}{ Variables } & \multicolumn{4}{|c|}{ Fall experience } & \multirow[t]{2}{*}{$x^{2}$} & \multirow[t]{2}{*}{$P$-value } \\
\hline & Yes & $\%$ & No & $\%$ & & \\
\hline \multicolumn{7}{|l|}{ Sex } \\
\hline Female & 33 & 51.6 & 19 & 29.7 & 0.044 & 0.835 \\
\hline Male & 8 & 12.5 & 4 & 6.3 & & \\
\hline \multicolumn{7}{|l|}{ Age (years) } \\
\hline$\geq 76$ & 20 & 31.3 & 13 & 20.3 & 0.354 & 0.552 \\
\hline $60-75$ & 21 & 32.8 & 10 & 15.5 & & \\
\hline \multicolumn{7}{|l|}{ Education } \\
\hline High school and above & 22 & 34.4 & 16 & 25.0 & 1.546 & 0.214 \\
\hline Primary school & 19 & 29.7 & 7 & 10.9 & & \\
\hline \multicolumn{7}{|l|}{ Income } \\
\hline Not enough & 7 & 10.9 & 2 & 3.1 & 0.856 & 0.355 \\
\hline Enough & 34 & 53.1 & 21 & 32.8 & & \\
\hline \multicolumn{7}{|l|}{ Eyesight problem } \\
\hline Yes & 36 & 56.3 & 21 & 32.8 & 0.185 & 0.667 \\
\hline No & 5 & 7.8 & 2 & 3.1 & & \\
\hline \multicolumn{7}{|c|}{ Using eyeglasses or contact lens } \\
\hline Yes & 24 & 37.5 & 15 & 23.4 & 0.276 & 0.599 \\
\hline No & 17 & 26.6 & 8 & 12.5 & & \\
\hline \multicolumn{7}{|l|}{ Bl scale } \\
\hline$\geq$ Mean & 31 & 48.4 & 9 & 14.1 & 8.366 & $0.004^{a}$ \\
\hline$<$ Mean & 10 & 15.6 & 14 & 21.9 & & \\
\hline \multicolumn{7}{|l|}{ TUG test } \\
\hline$\geq$ Mean & 18 & 28.1 & 10 & 15.6 & 0.001 & 0.974 \\
\hline$<$ Mean & 23 & 35.9 & 13 & 20.3 & & \\
\hline \multicolumn{7}{|l|}{ BBS } \\
\hline$\geq$ Mean & 22 & 34.4 & 13 & 20.3 & 0.049 & 0.825 \\
\hline$<$ Mean & 19 & 29.7 & 10 & 15.6 & & \\
\hline \multicolumn{7}{|c|}{ Using walking assistive devices } \\
\hline Yes & 12 & 18.8 & 12 & 18.8 & 3.298 & 0.069 \\
\hline No & 29 & 45.3 & $\mathrm{II}$ & 17.2 & & \\
\hline \multicolumn{7}{|c|}{ Physical activities $>30$ minutes, $\geq 3$ times/week } \\
\hline No & 9 & 14.1 & 10 & 15.6 & 3.271 & 0.071 \\
\hline Yes & 32 & 50.0 & 13 & 20.3 & & \\
\hline \multicolumn{7}{|l|}{ Comorbidities } \\
\hline$\geq 3$ & 19 & 29.7 & 9 & 14.1 & 0.311 & 0.577 \\
\hline$<3$ & 22 & 34.4 & 14 & 21.9 & & \\
\hline \multicolumn{7}{|l|}{ Medication risk } \\
\hline Yes & 33 & 51.6 & 19 & 29.7 & 0.044 & 0.385 \\
\hline No & 8 & 12.5 & 4 & 6.3 & & \\
\hline \multicolumn{7}{|c|}{ Knowledge toward fall prevention } \\
\hline$\geq$ Mean & 22 & 34.4 & 17 & 26.6 & 2.539 & 0.111 \\
\hline$<$ Mean & 19 & 29.7 & 6 & 9.4 & & \\
\hline \multicolumn{7}{|l|}{ Environmental hazard } \\
\hline$\geq 2$ & 21 & 32.8 & 6 & 9.4 & 3.816 & 0.051 \\
\hline$<2$ & 20 & 31.3 & 17 & 26.6 & & \\
\hline
\end{tabular}

Note: Significant at $P \leq 0.05$.

Abbreviations: BI, Barthel Index; TUG, Time Up and Go; BBS, Berg Balance Scale.

and security guards. Nurses and physical therapists were at their stations at regular and specific times. Pets were not allowed in both housings. There were some differences in service details: three meals a day and laundry services were free only for residents in single rooms, shared rooms, and bungalows. Some environmental hazards were observed in the rooms of participants such as uneven ground floor; disorganized room and kitchen; slippery floor; inadequate lighting at stairs, washroom, and from bed to washroom; and uneven ground surface in the garden (Table 1).

\section{Qualitative results Perception on fall}

\section{Fall is an unintentional event}

Fall is an accident. It happens and then the body hits the floor. [65-year-old lady] 
Table 4 Multivariate analysis of fall characteristics among active fall risk elderly living in senior housings $(\mathrm{N}=64)$

\begin{tabular}{|c|c|c|}
\hline Variables & OR $\left(95 \% \mathrm{Cl}^{*}\right)$ & $P$-value \\
\hline \multicolumn{3}{|l|}{ Sex } \\
\hline Female & $0.91(0.129-6.415)$ & 0.924 \\
\hline Male & 1 & \\
\hline \multicolumn{3}{|l|}{ Age (years) } \\
\hline$\geq 76$ & $0.97(0.212-4.431)$ & 0.967 \\
\hline $60-75$ & 1 & \\
\hline \multicolumn{3}{|l|}{ Education } \\
\hline High school and above & $0.44(0.064-3.030)$ & 0.405 \\
\hline Primary school & $\mathrm{I}$ & \\
\hline \multicolumn{3}{|l|}{ Income } \\
\hline Not enough & $2.32(0.264-20.459)$ & 0.447 \\
\hline Enough & $\mathrm{I}$ & \\
\hline \multicolumn{3}{|l|}{ Eyesight problem } \\
\hline Yes & $0.74(0.056-9.754)$ & 0.819 \\
\hline No & $\mathrm{I}$ & \\
\hline \multicolumn{3}{|c|}{ Using eyeglasses or contact lens } \\
\hline Yes & $0.73(0.125-4.206)$ & 0.720 \\
\hline No & 1 & \\
\hline \multicolumn{3}{|l|}{ BI scale } \\
\hline$\geq$ Mean & $6.00(1.238-29.100)$ & $0.026 *$ \\
\hline$<$ Mean & 1 & \\
\hline \multirow{2}{*}{\multicolumn{3}{|c|}{$\begin{array}{l}\text { TUG test (more score, better } \\
\text { balance) }\end{array}$}} \\
\hline & & \\
\hline$\geq$ Mean & $2.60(0.5 \mid 6-13.074)$ & 0.254 \\
\hline$<$ Mean & $\mathrm{I}$ & \\
\hline \multicolumn{3}{|c|}{ BBS (more score, poorer balance) } \\
\hline$\geq$ Mean & $0.34(0.052-2.182)$ & 0.254 \\
\hline$<$ Mean & 1 & \\
\hline \multicolumn{3}{|c|}{ Using walking assistive devices } \\
\hline Yes & $0.25(0.032-1.949)$ & 0.186 \\
\hline No & 1 & \\
\hline \multicolumn{3}{|c|}{ Physical activities $>30$ minutes, } \\
\hline \multicolumn{3}{|c|}{$\geq 3$ times/week } \\
\hline Yes & $3.05(0.584-15.889)$ & 0.186 \\
\hline No & 1 & \\
\hline \multicolumn{3}{|l|}{ Comorbidities } \\
\hline$\geq 3$ & $2.62(0.425-16.155)$ & 0.299 \\
\hline$<3$ & I & \\
\hline \multicolumn{3}{|l|}{ Medication risk } \\
\hline Yes & $0.49(0.068-3.512)$ & 0.477 \\
\hline No & 1 & \\
\hline \multicolumn{3}{|c|}{ Knowledge toward fall prevention } \\
\hline$\geq$ Mean & $0.44(0.075-2.609)$ & 0.369 \\
\hline$<$ Mean & 1 & \\
\hline \multicolumn{3}{|l|}{ Environmental hazard } \\
\hline$\geq 2$ & $6.33(1.242-32.290)$ & $0.026 *$ \\
\hline$<2$ & I & \\
\hline
\end{tabular}

Note: *Significant at $P \leq 0.05$.

Abbreviations: BI, Barthel Index; TUG, Time Up and Go; BBS, Berg Balance Scale.

I wanted to go to the market and I had a fall in front of the building when I was walking. Actually, that time I was looking somewhere else and I walked pretty fast. I did not notice that it was an uneven ground surface. I was not sure how I fell, maybe I did not lift my feet high enough. It was unintentional. I fell so fast, my arms were all scratched. [70-year-old lady]

\section{Loss of balance is a cause of fall}

Sometimes I lose my balance! I was about to fall many times but luckily I was able to hold the table. I would definitely fall if the table was not there. [80-year-old lady]

\section{Susceptibility depends on environment and health condition}

Yes, I might have had a chance to fall or stumble if I walk on wet floor. And the person who has walking problems is also at risk of falling. [67-year-old man]

\section{Fall severity varies according to the experiences}

Sometimes there is not effect from falling but most times it leads to injuries. My friend who is on the second floor had a fall last month. She fell while walking and was taken to the hospital. I'm very afraid of falling because I do not want to go to the hospital. If I have a broken bone it would be a big issue. I have to be very careful while walking. [67-year-old lady]

\section{Elderly perceived "be careful" is fall prevention}

Being careful was the main key to prevent the fall. When the main investigators asked "How do you prevent yourself from fall?" Most of the elderly replied "walking carefully" as the way to prevent the fall.

\section{Fall management}

Many elderly did not know what they should do when they fall

I just lie on the floor, or maybe ask someone to help. [63-year-old lady]

Nurse station in the senior housing is the first place to visit after a fall

If I fall, I would just try to stand by myself. If I got pain or felt injured, I would go to the nurse station in our senior housing. The nurse regularly comes here at 5.00 PM. I can ask for medication, but if it was severe, I would have to go to the hospital. [69-year-old lady]

Self-care is the most popular fall management among elderly

It did not affect me very much, so I did nothing. [65-yearold lady] 
I put medicine by myself. I have oil balm and I put it on my sprain. I did not go to the nurse station provided in our housing as well because it was a minor injury. It was recovered in few days. [61-year-old lady]

Meeting with health professionals depends on the severity of the injury, particularly when they felt pain

I had a fall several months ago when I was going outside. It was so painful. So, I went to the hospital. Then, I was in ankle splint for many weeks. [69-year-old lady]

\section{Fall prevention}

Fall can be prevented but elderly did not know how to do it

Yes, fall can be prevented. I think I should walk slower, and not hurry. That's all! [71-year-old lady]

\section{Environmental modification is fall prevention}

During my last room renovation, I ask the technicians to put more lights in my room at the walkway to the washroom and another light in my washroom, because I used to hit the table when I walked to the washroom. Luckily, I did not fall, but I felt a bit of a pain on my foot. I think proper lighting is necessary to help prevent fall. [70-year-old man]

\section{None of elderly concerned on the use of medication}

I don't know how medicine is related to fall. [61-yearold lady]

Exercise was good, but elderly had lack of knowledge as to which exercise improves balance

I think being healthy is better than being sick. I know in general exercise makes us stronger but I don't know which exercise or which position could help prevent the fall, may be walking? Arm-swing can help or not? [65-yearold lady]

Walking assistive devices increase stability, but elderly did not know how to choose appropriate walking assistive device

I think walking assistive device can help some people walk more stable. Personally, I don't use it because I still can walk by myself. I see someone use a cane, someone use a walker. I think it depends on their walking ability but I don't know how to choose it appropriately. [72-year-old lady]

\section{Discussion}

A mixed-method study was used to understand fall situations among physically active elderly at risk of a fall in senior housings in Bangkok, Thailand, and their perception of falls. The prevalence of falls was $64.1 \%$ among the participants in our study. The prevalence of fall in this study was higher than prevalence of fall among community dwelling in Thailand in 2014 (16.7\%). And prevalence of falls in this study was also higher than prevalence of falls reported among community care clients in Australia in 2018 (47.7\%). ${ }^{7}$ This higher prevalence might be due to different characteristics of participants in our study compared to others. Noticeably, the participants in our study had a higher risk of a fall because they had a history of falls and/or walking difficulty as inclusion criteria.

The higher prevalence of falls in this study than in similar studies cannot be explained by medical services as the two senior housings in this study already provide extra care such as in-house nurse and physical therapists at stations in regular specific times. These medical care services in the two housings correspond to luxury senior housings of private developers in Thailand. ${ }^{38,39}$ Moreover, the housings in this study provide a lower price of medical services than private developers with the same medical standard because the two housings belong to governmental body. ${ }^{39-41}$ The overall administration management and rotation of medical staffs of two housings in this study always inspected for quality assurance by the Thai Red Cross Society ${ }^{41}$ and Department of Older Persons, Ministry of Social Development and Human Security of Thailand. ${ }^{40}$ Both of these housings are learning and training centers for elderly care. ${ }^{40,41}$

Based on the researchers' observation, the two senior housings in this study were designed to be "user friendly" for the elderly, for instance, wide door for wheel chair and slope and stairs with handle and elevators. The bathroom had antislip floor. This corresponds to another independent living in USA in 2018. ${ }^{42}$ However, some environmental hazards were observed in the senior housings in this study such as uneven ground floor and untidy (messy) room of participants. In fact, majority of participants in this study (48.8\%) reported to have fallen outdoor in the residential area, for example walkway, garden, and yard. Contrary to this finding, in another recent study among senior housing residents in USA, ${ }^{43}$ it was shown that bathrooms were the most common place for environmental hazards linked to falls. Similarly, $55.5 \%{ }^{44}$ and $49.0 \%{ }^{7}-55.4 \%{ }^{45}$ of elderly dwelling in community in China and Australia, respectively, had fallen indoors at home. The findings reported in the literature showed that environmental hazards varied among settings. Thus, environmental assessment and modifications are required to reduce fall risk. ${ }^{20,27,46}$ 
The elderly who performed more physical ADL were more likely to have had experienced a fall than elderly who performed fewer activities daily. As in the univariate analysis, the factor that was significantly associated with falls among physically active elderly was a higher BI scale. This notion is supported by a previous study in Turkey in 2017 that found that the majority $(62.7 \%)$ of geriatric patients who were admitted in the emergency department were physically active before the fall event. ${ }^{47}$

The association of physical ADL measured by BI and fall was confirmed in the multivariate analysis. Even though environmental hazards were not significantly associated in the univariate analysis, it was found to be a significantly associated factor in multivariate analysis as an effect modifier toward fall among participants. We found that $70.7 \%$ of participants experienced a fall when they were walking, with the major causes of fall being stumbling (39\%) and loss of balance (39\%). This finding is in line with a previous study from Turkey, in 2017, that found that stumbling was the main mechanism of fall among geriatric patients who were admitted to the emergency department. ${ }^{47}$ Furthermore, a study on falls among a Thai elderly dwelling in a community in 2015 revealed that two-thirds of fall incidents usually occurred outside of their houses, especially while they were walking. ${ }^{48}$ While a study in Australia in 2018 revealed that falling while walking was considered a hidden contributor to pedestrian injury. ${ }^{49}$ Although walking is a preferred activity among elderly, ${ }^{50}$ walking with a safety aspect should be considered. ${ }^{49}$

According to qualitative findings, elderly perceived that a fall is an unexpected event that happens unintentionally when a person cannot control his or her body position and falls down, which is in line with the definition of WHO that defined fall as an event that results in a person coming to rest inadvertently on the ground or floor or other lower level. ${ }^{8}$

Most of the elderly perceived susceptibility that they were at risk of falling and raised health conditions and environmental hazards could affect fall such as wet floor, slope, and uneven ground surface. The elderly perceived that fall severity varied according to experiences and fall can be prevented by "being careful". This finding corresponded to a health belief model ${ }^{51}$ that elderly perceived susceptibility that they might be at risk of a fall and perceived the severity of a fall. Thus, elderly tend to change their behavior by being more careful in walking to avoid falling events.

Many elderly did not know what to do when they have fallen. The seeking of medical services from health professionals depends on the severity of injury, particularly when they feel very painful. This is in line with a previous study among elderly dwelling in community in Thailand in 2015 that pain after falling seems to be the most important reason for reporting a fall to physician and asking for treatment. ${ }^{48}$

Regarding fall prevention, elderly in this study stated that a fall can be prevented but did not know how to. This finding was in contrast with a previous study ${ }^{48}$ that was conducted among elderly dwelling in community in Thailand in 2015 that reported fall was an inevitable life event. The difference in perception on fall may be due to the residents' setting. The elderly in senior housings in this study received more information and encouragement to take care of themselves compared to the elderly living in community in the rural area. However, the elderly did not have knowledge on medication, choosing appropriate walking assistive devices, and exercise to prevent a fall. The fall prevention education was available only to the elderly who visited nurses and physical therapists for personal consult. Thus, education on fall prevention addressed on medication, walking assistive devices, and exercise is required for all residents in this study. ${ }^{52}$

\section{Strengths, limitations, and practical recommendations}

The first strength of our study is that we used the validated and reliable standard tools to screen fall risk in elderly population. ${ }^{33-35}$ Second, the characteristics of fall were investigated using both the quantitative and qualitative approaches so that the strong capture of situations and perceptions of fall among active fall risk elderly could be obtained. However, some limitations also existed in our study. First, we only recruited elderly from government senior housings. Second, the sample size was insufficient. Further studies may conduct the research using a larger sample size from both government and private senior housings.

As a practical recommendation, uneven ground surface was addressed as a remarkable environmental hazard in the housings in Thailand. Thus, environmental modification is required. Moreover, the housings may provide routine environmental assessment to reduce risk of falls among residents.

Fall risk screening should be conducted annually ${ }^{53}$ to find elderly who are at fall risk in order to provide appropriate intervention. According to the STEADI algorithm for fall risk screening, assessment, and intervention, ${ }^{26}$ most of the elderly in this study were classified into the low and moderate fall risk category. Some recommended interventions for this group were education, vitamin $\mathrm{D} \pm$ calcium, and Otago exercise. ${ }^{22,23}$ While for those who were defined to have a high risk of experiencing a fall (had balance problem 
together with experiencing of fall $\geq 2$ times and/or had injury) were recommended interventions such as doing medication review, providing a cognitive screening, postural dizziness/ hypotension checking, mobility aid, foot and footwear checking, visual checking, health education, and referring to a physical therapist to improve gait or exercise.

This study was conducted among the elderly who were at risk of falls in government senior housings. The findings from this study are beneficial for architecture and for developing fall prevention interventions as services package for elderly residents in the future.

\section{Conclusion}

The prevalence of fall among active fall risk elderly in senior housings was relatively high in our study area. A higher BI scale and $\geq 2$ environmental hazards were found to be associated factors of fall among this frail population. The elderly perceived that a fall could be avoided even though they did not know how to prevent it. The intervention that focuses on environmental modifications, balancing enchantment, and fall education are highly required and recommended.

\section{Acknowledgments}

This study was funded by the 90th Anniversary Chulalongkorn University (Ratchadaphiseksomphot Endowment Fund) and the Thailand Research Fund. The authors thank Dr Bayu Anggileo Pramesona for proofreading this paper.

\section{Disclosure}

The authors report no conflicts of interest in this work.

\section{References}

1. United Nations. World Population Ageing 2017 Highlights. New York: Department of Economic and Social Affirs, United Nations (UN), New York; 2017. Available from: http://www.un.org/en/development/ desa/population/publications/pdf/ageing/WPA2017_Highlights.pdf. Accessed June 12, 2018.

2. Foundation of Thai Gerontology Research and Development Institute IfPaSR, Mahidol University. Situation of the Thai Elderly in 2016. Bangkok: Foundation of Thai Gerontology Research and Development Institute; 2017. Available from: http://www.ipsr.mahidol.ac.th/ipsrbeta/ en/BookReport.aspx?Year=2017

3. World Health Organization [homepage on the Internet]. Falls; 2018. Available from: http://www.who.int/news-room/fact-sheets/detail/falls. Accessed June 12, 2018.

4. National Center for Injury Prevention and Control. Preventing Falls: A Guide to Implementing Effective Community-Based Fall Prevention Programs. 2nd ed. Atlanta, GA: Centers for Disease Control and Prevention; 2015. Available from: https://www.cdc.gov/homeandrecreationalsafety/ pdf/falls/fallpreventionguide-2015-a.pdf. Accessed June 12, 2018.

5. Wu H, Ouyang P, Hong Wu PO. Fall prevalence, time trend and its related risk factors among elderly people in China. Arch Gerontol Geriatr. 2017;73:294-299.
6. Buckinx F, Croisier JL, Reginster JY, et al. Prediction of the Incidence of Falls and Deaths Among Elderly Nursing Home Residents: The SENIOR Study. J Am Med Dir Assoc. 2018;19(1):18-24.

7. Burton E, Lewin G, O'Connell H, Hill KD. Falls prevention in community care: 10 years on. Clin Interv Aging. 2018;13(13):261-269.

8. World Health Organization (WHO). WHO Global report on falls Prevention in older Age. 2007. Available from: http://www.who.int/ ageing/publications/Falls_prevention7March.pdf. Accessed June 12, 2018.

9. Aekplakarn W. Thai National Health Examination Survey. 2014. Available form: http://thaitgri.org/?p=37869. Accessed September 23, 2017.

10. Hendrie D, Hall SE, Legge M, Arena G. Injury in Western Australia: The health system costs of falls in older adults in Western Australia. Perth, Western Australia. Western Australian Government. 2003. Available from: http://www.health.wa.gov.au/docreg/Education/Prevention/ Injury_Prevention/HP1695_injury_WA_health_system_costs_of_falls. pdf. Accessed June 12, 2018.

11. Nurmi I, Lüthje P. Incidence and costs of falls and fall injuries among elderly in institutional care. Scand J Prim Health Care. 2002; 20(2):118-122.

12. Roudsari BS, Ebel BE, Corso PS, Molinari NA, Koepsell TD. The acute medical care costs of fall-related injuries among the U.S. older adults. Injury. 2005;36(11):1316-1322.

13. Scott VJ. Technical report: hospitalizations due to falls among Canadians age 65 and over. Minister of. Canada: Public Works and Government Services; 2005. Available from: http://www.ndss-snsd. gc.ca/seniors-aines/alt-formats/pdf/publications/pro/injury-blessure/ seniors_falls/technical-report-injury_e.pdf. Accessed June 12, 2018.

14. Florence CS, Bergen G, Atherly A, Burns E, Stevens J, Drake C. Medical Costs of Fatal and Nonfatal Falls in Older Adults. $J$ Am Geriatr Soc. 2018;66(4):693-698.

15. Benjawan Sophonratanapokin YS, Soonthorndhada K. Effect on the living environment on falls among the elderly in Thailand South East Asian. J Trop Med Public HealtH. 2012;43(6):1537-1547.

16. Stevens JA. Fatalities and Injuries From Falls Among Older Adults, United States, 1993-2003 and 2001-2005. J Am Med Assoc. 2007; 297(1):32-33.

17. Bird ML, Pittaway JK, Cuisick I, Rattray M, Ahuja KD. Age-related changes in physical fall risk factors: results from a 3 year follow-up of community dwelling older adults in Tasmania, Australia. Int J Environ Res Public Health. 2013;10(11):5989-5997.

18. Hughes RG, editor. Fall and injury prevention. Patient Safety and Quality: An Evidence-Based Handbook for Nurses. Rockville, MD: Agency for Healthcare Research and Quality; 2008.

19. Dhargave P, Sendhilkumar R, Pradnya Dhargave RS. Prevalence of risk factors for falls among elderly people living in long-term care homes. Journal of Clinical Gerontology and Geriatrics. 2016;7(3):99-103.

20. Gillespie LD, Robertson MC, Gillespie WJ, et al. Interventions for preventing falls in older people living in the community. Cochrane Database Syst Rev. 2012;(9):CD007146.

21. Thanyaluck Anothaisinthawee ST, Srisawan P, Yothasamut C. Fall Prevention Medication. Research Institution and Elderly Develepment Foundation; 2012. Available from: www.thaitgri.org. Accessed May 30, 2016.

22. UK Age [webpage on the Internet]. Falls Prevention Exercise - Following the Evidence. UK; 2013. Available from: www.ageuk.org.uk. Accessed September 13, 2018.

23. A John Campbell MCR. Otago Exercise Programme to Prevent Falls in Older Adults. Otago Medical School, University of Otago. 2003. Available from: https://www.acc.co.nz/assets/injury-prevention/ acc1162-otago-exercise-manual.pdf. Accessed June 12, 2018. 
24. Areerat Suphutitada RB, Priwan Sathanon, Elderly Handbook: Good Walking, No Falling. Nonthaburi: Health Systems Research Institute (HSRI); 2016. Available from: www.dms.moph.go.th/dmsweb/ cpgcorner/2009021784231.pdf. Accessed September 20, 2017.

25. The Urban Land Institute. Emerging Trends in Real Estate Asia Pacific 2018. Washington, DC: The Urban Land Institute; 2018. Available from: https://asia.uli.org/wp-content/uploads/sites/126/2017/11/ETAP2018.pdf. Accessed June 12, 2018.

26. Centers for Disease Control and Prevention. Algorithm for Fall Risk Screening, Assessment, and Intervention. Center for Disease Control and Prevention NCfipac. USA: Center for Disease Control and Prevention, National Center for injury prevention and control; 2017. Available from: https://www.cdc.gov/steadi/pdf/STEADI-Algorithm-508.pdf. Accessed June 12, 2018.

27. Checklist for safety [homepage on the Internet]: A home fall prevention checklist for older adults Center for Disease Control and Prevention, National Center for injury prevention and control, U.S. Department of Health \& Human Services; 2016. Available from: https:/www.cdc. gov/steadi/. Accessed April 1, 2017.

28. Barthel Index of Activities of Daily Living University of Iowa Health Care; 1988. Available from: https://www.healthcare.uiowa.edu/igec/ tools/function/barthelADLs.pdf. Accessed October 16, 2015.

29. Shumway-Cook A, Baldwin M, Polissar NL, Gruber W. Predicting the probability for falls in community-dwelling older adults. Phys Ther. 1997;77(8):812-819.

30. Barthel Index (BI). Available from: https://commondataelements.ninds. nih.gov/Doc/NOC/Barthel_Index_NOC_Public_Domain.pdf. Accessed September 21, 2015.

31. Piyapat DRM, Prasertporn J, Somluck P, Saowaluck J, Ampai Y. The Inter-rater Reliability of Barthel Index (Thai Version) in Stroke Patients. J Thai Rehabil. 2006;16(1):1-9.

32. IoG M. Medical Practice Guideline for Prevention/Evaluation Fall in Elderly Thailand Health Department. Thailand: Ministry of Publc Health; 2008. Available from: www.dms.moph.go.th/dmsweb/ cpgcorner/2009021784231.pdf. August 12, 2017.

33. Sebastião E, Sandroff BM, Learmonth YC, Motl RW. Validity of the Timed Up and Go Test as a Measure of Functional Mobility in Persons With Multiple Sclerosis. Arch Phys Med Rehabil. 2016;97(7): 1072-1077.

34. Chan PP, Si Tou JI, Tse MM, Ng SS. Reliability and Validity of the Timed Up and Go Test With a Motor Task in People With Chronic Stroke. Arch Phys Med Rehabil. 2017;98(11):2213-2220.

35. Alexandre TS, Meira DM, Rico NC, Mizuta SK. Accuracy of Timed Up and Go Test for screening risk of falls among community-dwelling elderly. Rev Bras Fisioter. 2012;16(5):381-388.

36. Major MJ, Fatone S, Roth EJ. Validity and reliability of the Berg Balance Scale for community-dwelling persons with lower-limb amputation. Arch Phys Med Rehabil. 2013;94(11):2194-2202.

37. Park SH, Lee YS, Seong-Hi Park Y-SL. The Diagnostic Accuracy of the Berg Balance Scale in Predicting Falls. West J Nurs Res. 2017;39(11): $1502-1525$.
38. Strong potential for luxury senior housing market in Thailand [homepage on the Internet]. JLL. 2017. Available from: http:/www.jll.co.th/ thailand/en-gb/news/585/strong-potential-for-luxury-senior-housingmarket-in-thailand. Accessed September 13, 2018.

39. Absolute Living Thailand [homepage on the Internet]. 2018. Available from: http://www.absolutelivingthailand.com/service.php. Accessed August 10, 2018.

40. banbangkhae [homepage on the Internet]. Department of Older Persons. Thailand: Ministry of Social Development and Human Security; 2018. http://banbangkhae.go.th/demo/index.php. Accessed September 13, 2018.

41. Introduction to Sawangkanivej The Thai Red Cross Society [homepage on the Internet]; 2017. Available from: http://centralb.redcross.or.th/. Accessed August 10, 2018.

42. Helpguilde.org S.H [homepage on the Internet]; 2018. Available from: https://www.helpguide.org/articles/alzheimers-dementia-aging/seniorhousing.htm. Accessed August 2, 2018.

43. Kim D, Portillo M. Fall Hazards Within Senior Independent Living: A Case-Control Study. HERD. Epub 2018 Jan 01.

44. Er Y, Duan L, Ye P, et al. Epidemiologic characteristics of fall in old population: Results from national injury surveillance in China, 2014. Zhonghua Liu Xing Bing Xue Za Zhi. 2016;37(1):24-28.

45. Miu J, Curtis K, Balogh ZJ. Profile of fall injury in the New South Wales older adult population. Australas Emerg Nurs J. 2016;19(4): 179-185.

46. Burton E, Lewin G, O'Connell H, Hill KD. Falls prevention in community care: 10 years on. Clin Interv Aging. 2018;13:261-269.

47. Cimilli Ozturk T, Ak R, Unal Akoglu E, Onur O, Eroglu S, Saritemur M. Factors Associated With Multiple Falls Among Elderly Patients Admitted to Emergency Department. Int J Gerontol. 2017;11(2):85-89.

48. Boongird C, Ross R, Chitima Boongird RR. Views and Expectations of Community-Dwelling Thai Elderly in Reporting Falls to Their Primary Care Physicians. J Appl Gerontol. 2017;36(4):480-498.

49. Oxley J, O’Hern S, Burtt D, Rossiter B, Jennifer Oxleya SOH, Duane Burtt BR. Falling while walking: A hidden contributor to pedestrian injury. Accid Anal Prev. 2018;114:77-82.

50. Burton E, Lewin G, Boldy D. Physical activity preferences of older home care clients. Int J Older People Nurs. 2015;10(3):170-178.

51. Charles Abraham PS. The health belief model. In: Mark Conner PN, editor. Predicting and Changing Health Behaviour Research and Practice with Social Cognition Models. 3rd ed. New York, NY: Open University Press McGraw-Hill Education; 2015:30-69.

52. Smitesh Gutta AJ, Chakraborty A, Alexander AM. Study on the knowledge, attitudes and practices regarding prevention of recurrent falls in the elderly. Journal of Dental and Medical Sciences. 2013;9(3):32-38.

53. Gaboreau Y, Imbert P, Jacquet JP, Royer de Vericourt G, Couturier P, Gavazzi G. Barriers to and promoters of screening for falls in elderly community-dwelling patients by general practitioners: a large crosssectional survey in two areas of France. Arch Gerontol Geriatr. 2016; 65:85-91.
Clinical Interventions in Aging

\section{Publish your work in this journal}

Clinical Interventions in Aging is an international, peer-reviewed journal focusing on evidence-based reports on the value or lack thereof of treatments intended to prevent or delay the onset of maladaptive correlates of aging in human beings. This journal is indexed on PubMed Central, MedLine,

\section{Dovepress}

CAS, Scopus and the Elsevier Bibliographic databases. The manuscript management system is completely online and includes a very quick and fair peer-review system, which is all easy to use. Visit http://www.dovepress. com/testimonials.php to read real quotes from published authors. 